\title{
Ultrasonographic and resistance index evaluation of nails in psoriatic arthritis, psoriasis, and control groups: a cross- sectional study
}

Samanta Daiana De Rossi ${ }^{1,2^{*}}$ (D, José Alexandre Mendonça ${ }^{3}$, Penelope Ester Palominos ${ }^{1}$, Charles Lubianca Kohem ${ }^{1}$, Tania Ferreira Cestari ${ }^{2}$ and Rafael Mendonça da Silva Chakr ${ }^{1}$

\begin{abstract}
Background: Nail psoriasis occurs frequently in patients with psoriatic disease, it can lead to functional impairment, pain, discomfort, decreased quality of life and can also be a predictor for the development of arthritis. Early recognition of this condition can provide early and effective treatment and prevent structural impairment. This study aims to identify nail ultrasonographic characteristics in three groups: psoriasis (PsO), psoriatic arthritis (PsA) and controls patients, to determine if the ultrasonography (US) can identify early signs of nail psoriatic impairment or local inflammation. We conducted nail US to determine nail matrix resistance index (NMRI), nail bed resistance index (NBRI), and power Doppler (PD) and grayscale (GS) parameters in these 3 groups.
\end{abstract}

Methods: Single-center, cross-sectional study. GS, PD, and spectral doppler images of bilateral 2nd and 3rd fingernails were acquired from 35 PsO, 31 PsA, and 35 controls patients. An US equipment with an $18 \mathrm{MHz}$ linear transducer for GS and $8.0 \mathrm{MHz}$ for PD was used. PD, NMRI, NBRI, nail plate thickness (NPT), nail bed thickness (NBT), nail matrix thickness (NMT), and morphostructural characteristics of the trilaminar structure (TS) were evaluated in saved images, blind.

Results: Mean NMRI and NBRI did not differ between groups. Linear regression analysis detected no relationships between PsO or PsA and NMRI or NBRI. Nail PD grade did not differ between groups. Type I and IV TS changes were more frequent in PsO; types II and III changes were more frequent in PSA $(p<0.001)$. NPT was greater in PsA and PsO groups than controls: PsA $0.73 \pm 0.14 \mathrm{~mm}$, PsO $0.72 \pm 0.15 \mathrm{~mm}$, Controls $0.67 \pm 0.10 \mathrm{~mm}(p=0.001)$.

Conclusion: Echographic TS characteristics of the nail plate and NPT evaluated by GS are useful and can distinguish PSO and PsA nails from controls. NMRI, NBRI, and US nail microcirculation parameters could not distinguish psoriatic nails.

Trial registration: 72762317.4.0000.5327 (Certificate of Presentation of Ethical Appreciation - CAAE - Plataforma Brasil) Avaiable in https://plataformabrasil.saude.gov.br/login.jsf.

Keywords: Doppler ultrasonography, Nails, Psoriasis, Psoriatic arthritis, Ultrasonography

\footnotetext{
* Correspondence: samantaderossi@gmail.com

'Division of Rheumatology, Hospital de Clínicas de Porto Alegre,

Universidade Federal do Rio Grande do Sul, Porto Alegre, Brazil

${ }^{2}$ Divisiont of Dermatology, Hospital de Clínicas de Porto Alegre, Universidade

Federal do Rio Grande do Sul, Porto Alegre, Brazil

Full list of author information is available at the end of the article
}

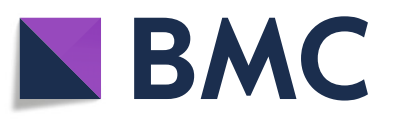

(c) The Author(s). 2021 Open Access This article is licensed under a Creative Commons Attribution 4.0 International License, which permits use, sharing, adaptation, distribution and reproduction in any medium or format, as long as you give appropriate credit to the original author(s) and the source, provide a link to the Creative Commons licence, and indicate if changes were made. The images or other third party material in this article are included in the article's Creative Commons licence, unless indicated otherwise in a credit line to the material. If material is not included in the article's Creative Commons licence and your intended use is not permitted by statutory regulation or exceeds the permitted use, you will need to obtain permission directly from the copyright holder. To view a copy of this licence, visit http://creativecommons.org/licenses/by/4.0/. 


\section{Background}

Nail involvement by psoriatic disease occurs in $40-45 \%$ of patients with skin psoriasis ( $\mathrm{PsO}$ ) and in around $80.5 \%$ of patients with psoriatic arthritis (PsA) [1, 2]. The lifetime incidence of nail involvement in psoriatic patients is estimated to be between 80 and 90\% [3]. Furthermore, nail psoriasis can lead to functional impairment, pain, discomfort, decreased quality of life and can also be a predictor for the development of arthritis $[4,5]$. Therefore, early recognition of this condition is essential to facilitate early and effective treatment and to prevent structural impairment.

Ultrasonography (US) is considered a highly promising method to visualize nail disease. However, there is no consensus yet about which parameters and features can provide accuracy in the evaluation of nail psoriasis [6].

Examination of the normal structure of the nail on grayscale (GS) US images can identify the nail plate $(\mathrm{NP})$, the nail bed (NB), and the nail matrix (NM). The $\mathrm{NP}$ is a trilaminar structure (TS) comprising dorsal and ventral plates that appear as 2 hyperechoic parallel lines with a virtual hypoechoic space in between. The nail bed is a hypoechoic band between the ventral nail plate and the distal phalanx margin. The nail matrix is an isoechoic (soft gray) region at the proximal end of the nail bed in the region below the proximal nail fold. The phalanx is the deepest structure, appearing as a hyperechoic band, located immediately below the nail bed [7, 8].

US examination can detect many changes to psoriatic nails, even in the absence of clinical findings [9-13]. Wortsman et al. described and classified 4 types of US TS changes, ranging from the earliest to the most severe: focal hyperechoic involvement of the ventral plate without involvement of the dorsal plate (type I), loosening of the borders of the ventral plate (type II), appearance of wavy plates (type III), and loss of definition on both plates (type IV) (Fig. 1) [8]. The NB is usually thickened in psoriatic nails $(2.0-3.0 \mathrm{~mm})[11,14]$.

Power Doppler (PD) can identify signals in psoriatic nails [14]. Gutierrez et al. have developed a scoring system to quantify PD signal activity, as follows: $0=$ no signal, $1=$ confluent signal in $<25 \%$ of the area evaluated, $2=$ confluent signal in $>25 \%$ and $<50 \%, 3=$ confluent signal in $>50 \%$ [15].

The Spectral Doppler (SDo) technique can differentiate between low and high peripheral resistance by assessing the movement of red blood cells in small blood vessels with low velocity flow. Peripheral resistance is expressed numerically by the Resistance Index (RI), which is assessed as the following ratio: (Qs - Qd) / Qs, where Qs represents the maximum flow velocity in systole and Qd the end diastolic flow velocity (Fig. 2). In synovitis, RI ratios range from 0 to 1 , high values mean high resistance, which is normal in resting musculoskeletal tissues [16-19].

This study is designed to identify differences between $\mathrm{PsO}$ and PsA patients and controls in terms of NM and NB microcirculation and US nail anatomy, using GS, $\mathrm{PD}$, and SDo, with a primary focus on RI measurement. If present, such differences could provide the basis for a noninvasive method for early detection of inflammation in nail apparatus of PsA and PsO patients, enabling early treatment and prevention of joint deterioration.

\section{Methods}

This was a single-center, cross-sectional, observational study, conducted in the Rheumatology and Dermatology outpatient clinics at the Hospital de Clínicas de Porto Alegre, RS, Brazil, from October 2017 to June 2018.
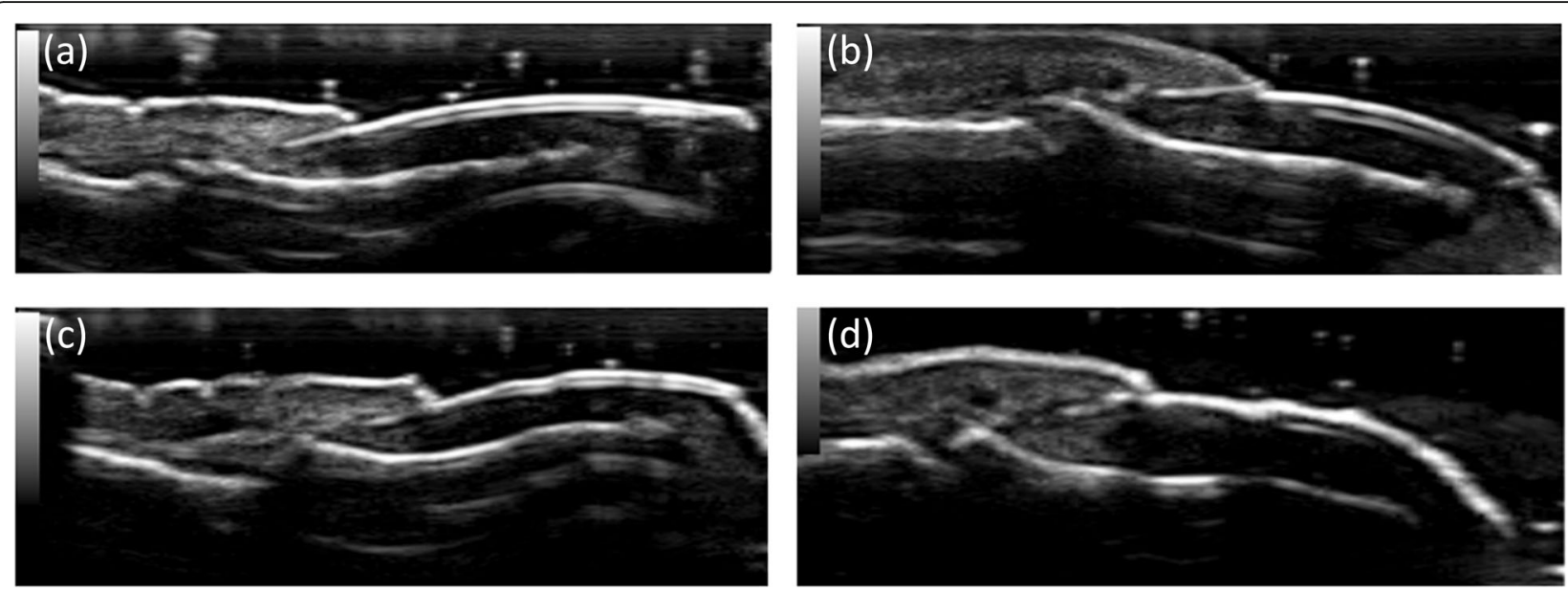

Fig. 1 Wortsman's classification of psoriatic nail changes in the trilaminar structure of nail plate. Legend: (a) hyperechoic deposits in ventral plate; (b) lost of definition of the ventral plate, (c) wavy plates, (d) loss of definition of both plates. Authors' collection 


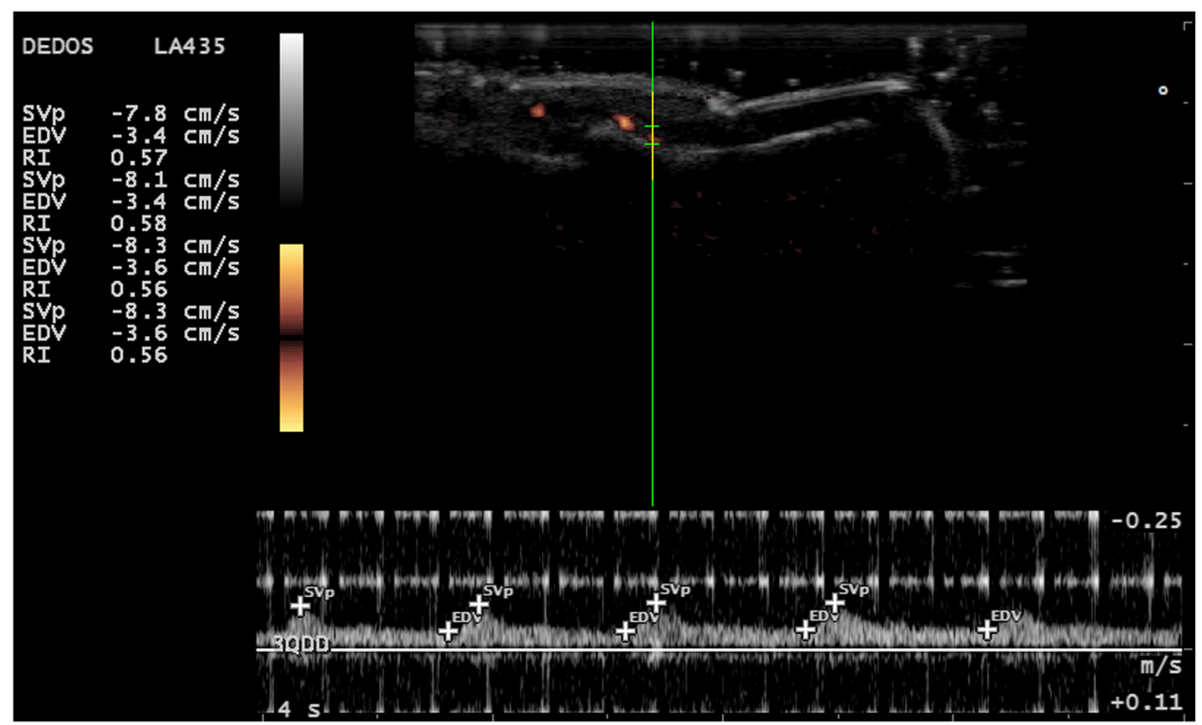

Fig. 2 RI measure by spectral doppler. Legend: SVp: maximum blood flow velocity in systole. EDV: diastolic blood flow velocity. Rl: resistence index. Authors' collection

Sample size was calculated to detect an effect size of 0.36 in NMRI measures between groups, considering a Standard Deviation (SD) of 0.41 [20]. This calculation was performed using SAS Studio and considering power of $80 \%$ and $\alpha=0.05$. Age was included as a covariate in the sample size calculation because previous studies suggest that it can influence evaluation of nail structure with Doppler [12, 21]. A low degree of correlation (0.2) was used because there is no data in the literature regarding the correlation between age and RI. The result of the sample size calculation was 81 patients, 27 in each group.

PsA patients were consecutively enrolled during their routine medical consultations. $\mathrm{PsO}$ patients without joint symptoms or complaints and controls were matched to the PsA group by age and gender. Participants for the control group were selected from among patients at dermatology and anesthesia outpatients clinics and hospital staff.

Participants were at least 18 years-old; to be eligible for the PsA group, they had to fulfill the CASPAR criteria [22]; for the $\mathrm{PsO}$ group, patients should have a diagnosis of cutaneous $\mathrm{PsO}$ and no signs or symptoms of present or past joint disease (arthritis, enthesitis or synovitis). Patients with fibromyalgia were excluded from the PsA group because it is difficult to differentiate between pain caused by this condition and enthesitic pain. Additional exclusion criteria for all groups included: other inflammatory joint diseases, dermatological or systemic diseases that could modify the nail structure; and severe pulmonary, vascular or hematological diseases that can interfere with circulatory evaluation [21]. Diabetes Mellitus (DM), High
Blood Pressure (HBP) and smoking were not exclusion criteria for any of the groups.

The National Research Ethics Committee of Brazil approved this study under registration number 72762317.4.0000.5327, and informed consent was obtained from all participants before clinical and sonographic examinations.

\section{Clinical evaluation}

Patients answered a questionnaire about demographic and disease characteristics. On the same day, a dermatologist assessed the percentage of affected body surface area (BSA) and calculated the Psoriasis Area and Severity Index (PASI) [23] and the Nail Psoriasis Severity Index (NAPSI) [24]. Psoriatic arthritis activity was assessed by a rheumatologist during the medical consultation, using the Disease Activity in Psoriatic Arthritis (DAPSA) score [25], the Maastricht Ankylosing Spondylitis Enthesis Score (MASES) [26], the Minimal Disease Activity (MDA) criteria [27], a patient Visual Analog Scale (VAS) for pain, and a global patient VAS [28], plus blood test results for $\mathrm{C}$ reactive protein (CRP) and Erythrocyte Sedimentation Rate (ESR).

\section{Ultrasonographic assessment of nails}

Examinations were performed using a MyLab 50 system (Esaote Biomedica, Genova, Italy), equipped with a linear 10 to $18 \mathrm{MHz}$ transducer for GS and a 6.6 to $8.0 \mathrm{MHz}$ transducer for PD. The imaging parameters for Doppler ultrasound examinations were pulse repetition frequency of $700 \mathrm{~Hz}$ with color gain maximized for optimal sensitivity while avoiding excessive color noise. 
Sonographic examinations were performed in a room with temperature between $22^{\circ} \mathrm{C}$ and $26^{\circ} \mathrm{C}$, after a 10 min period at rest. The patient was seated, with forearms, hands and fingers in a neutral and relaxed position on the table and nails were scanned in the longitudinal plane. A thick gel layer was applied to provide an adequate acoustic interface and to avoid compression of the structures. The 2nd and 3rd fingernails of both hands were evaluated.

Images were saved and measures and evaluations were performed at a later date, without identification of the patient, by the same researcher who conducted the US examinations. In GS, the following structures were assessed: 1) the trilaminar appearance of the NP, graded according to Wortsman's classification of changes in psoriatic nails [8], 2) nail plate thickness (NPT), measured at the thickest point, 3) nail bed thickness (NBT), measured at the middle third of the NP, 4) nail matrix thickness (NMT), defined as the hypoechoic region below the proximal nailfold, above the cortex of the distal phalanx, determined by a perpendicular line to the bone profile [8, 12, 29] (Fig. 3).

Presence or absence of blood flow signal in the NM and the NB were evaluated in PD images and classified according to the Gutierrez score [15]. The MyLabDesktop software enables automatic calculation of RI in Spectral wave analysis of a saved image when the cursor is placed at maximum systolic velocity and end diastolic flow velocity (Fig. 2). Three measurements were taken and the arithmetic mean was considered the RI. All measurements were taken and all scores were calculated by the same researcher and agreement with an experienced sonographer was tested for 20 selected images of the nail unit. Cohen's Kappa [30] was 0.51.

\section{Statistical analyses}

Quantitative variables are expressed as mean \pm SD and categorical variables as absolute frequencies and percentages. Comparisons between independent means were analyzed using ANOVA or the Kruskal-Wallis test.
Associations between categorical variables were calculated using the chi-squared test or Fisher's exact test. Correlations between quantitative variables were analyzed with Spearman's correlation coefficients. Linear regression analysis was performed with each of the quantitative variables. Statistical significance was defined as a $p$ value $\leq 0.05$. SPSS 21.0 was used for statistical analysis.

\section{Results}

Thirty-five patients with PsO; 31 with PsA, and 35 controls were enrolled on the study. One hundred and twenty-three nails were evaluated in the PsA group (76 with clinical nail psoriasis); 139 in the $\mathrm{PsO}$ group (60 with clinical nail psoriasis); and 138 in the control group. Patient's demographic and disease characteristics are summarized in Table 1 . No gender or age differences were found between groups.

There were no differences between the groups in terms of mean NMRI, NBRI, NBT, or NMT. There was no statistical difference between groups in nail $\mathrm{PD}$ grades. Mean $\mathrm{NPT} \pm \mathrm{SD}(\mathrm{mm})$ was higher in the PsA and $\mathrm{PsO}$ groups than in the control group: $0.73 \pm 0.14$ in the PsA group, $0.72 \pm 0.15$ in the $\mathrm{PsO}$ group, and $0.67 \pm$ 0.10 in the control group $(p=0.001)$. (Table 2$)$.

Patients undergoing systemic treatment for either PsO or PsA did not present differences in NMRI, NBRI, NPT, NBT and NMT measurements when compared to patients not undergoing systemic treatment. The same comparison was made both within and between $\mathrm{PsO}$ and PsA groups and no differences were found.

NPT was the only measurement to show different results when patients with clinical nail psoriasis - mean $0.75 \mathrm{~mm}$ (CI 0.71-0.80) - and patients without clinical nail involvement - $0.68 \mathrm{~mm}$ (CI $0.67-0.72$ ) - were compared $(p=0,042)$. No differences were found when the same comparison was made between $\mathrm{PsO}$ and PsA groups.

The TS evaluation was conducted using the Wortsman classification [8]. In the control group, 137 (99.3\%) nails

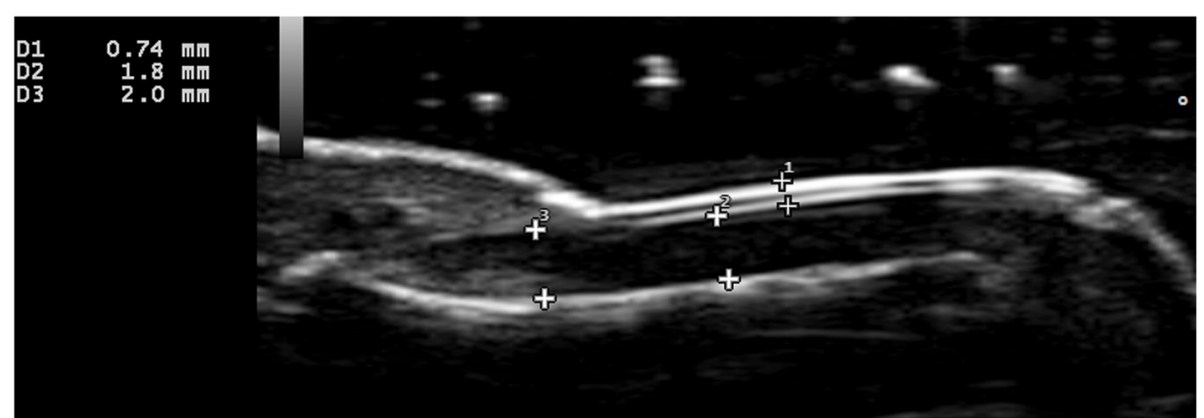

Fig. 3 Measures of nail plate, nail bed and nail matrix thickness in US gray scale. Legend: Nail plate thickness measure (1); nail bed thickness measure (2) and nail matrix thickness measure (3). Authors' collection 
Table 1 Demographic and Disease characteristics in each group

\begin{tabular}{|c|c|c|c|c|}
\hline & $\begin{array}{l}\text { PsA } \\
(n=31)\end{array}$ & $\begin{array}{l}\text { PsO } \\
(n=35)\end{array}$ & $\begin{array}{l}\text { Controls } \\
(n=35)\end{array}$ & $p$ value* \\
\hline \multicolumn{5}{|l|}{ Gender - n(\%) } \\
\hline Female & $16(51.6)$ & $18(51.4)$ & $21(60.0)$ & 0.767 \\
\hline Male & $15(48.4)$ & $17(48.6)$ & $14(40.0)$ & \\
\hline \multicolumn{5}{|l|}{ Age (years) - } \\
\hline mean $\pm S D$ & $53.03 \pm 9.64$ & $54.46 \pm 11.43$ & $53.37 \pm 10.80$ & 0.521 \\
\hline Havy manual labor - n(\%) & $25(80.6)$ & $28(80.0)$ & $25(71.4)$ & 0.692 \\
\hline \multicolumn{5}{|l|}{ Comorbidities - n(\%) } \\
\hline $\mathrm{HBP}$ & $12(38.7)$ & $13(37.1)$ & $13(37.1)$ & 0.99 \\
\hline DM & $7(22.6)$ & $8(22.9)$ & $3(8.6)$ & 0.217 \\
\hline Smoking & $5(16.1)$ & $5(14.3)$ & $3(8.6)$ & 0.627 \\
\hline PsO Family History- n(\%) & $11(35.5)$ & $19(54.3)$ & $3(8.6)$ & $<0.001$ \\
\hline Mean duration of cutaneous PsO (years) - mean \pm SD & $18.81 \pm 10.73$ & $16.16 \pm 10.33$ & - & 0.311 \\
\hline PASI - m [P25\% - P75\%] & $\begin{array}{l}(n=13) \\
1.0[0.70-4.15]\end{array}$ & $\begin{array}{l}(n=24) \\
3.75[1.15-5.83]\end{array}$ & - & 0.171 \\
\hline With clinical nail involvment - n(\%) & $15(48.4)$ & $19(54.3)$ & - & 0.805 \\
\hline NAPSI - m [P25\% - P75\%] & $\begin{array}{l}(n=15) \\
20[4-34]\end{array}$ & $\begin{array}{l}(n=19) \\
11[5-33]\end{array}$ & - & 0.891 \\
\hline \multicolumn{5}{|l|}{ PsO/PsA Current Treatment n(\%) } \\
\hline MTX & $18(58.1)$ & $17(48.6)$ & - & 0.600 \\
\hline Phototherapy & $3(9.7)$ & $7(20.0)$ & - & 0.410 \\
\hline Immunobiological & $10(32.3)$ & $4(11.4)$ & - & 0.078 \\
\hline Corticosteroids & $6(19.3)$ & $0(0.0)$ & - & 0.003 \\
\hline Any systemic treatment & $27(77.1)$ & $21(60.0)$ & - & 0.029 \\
\hline
\end{tabular}

Legend: $n$ absolute frequency of patients, SD standard deviation, $m$ median, [P25\% - P75\%] percentile $25 \%$ - percentile $75 \%), P s O$ psoriasis, PsA psoriatic arthritis, $H B P$ high blood pressure, DM diabetes mellitus, PASI psoriasis area severity index, NAPSI nail psoriasis severity index, MTX methotrexate, * significance fixed on $p<0,05$

had no TS changes. In the PsO group, 32 nails had changes in this structure, 9 type I, 5 type II, 7 type III, and 11 type IV. In the PsA group, there were also 32 nails with TS changes, 4 type I, 15 type II, 9 type III and 4 type IV.

Correlations between disease activity classifications and the variables studied were as follows: NBT with MASES $\left(r_{\mathrm{s}}=0.228 p<0.001\right)$; NPT with NAPSI $\left(\mathrm{r}_{\mathrm{s}}=\right.$ $0.258 p<0.001)$ and with MASES $\left(\mathrm{r}_{\mathrm{s}}=0.246 p=0.006\right)$. Patients in MDA (Minimal Disease Activity) had lower NPT $\left(r_{s}=-0.307, p=0.002\right)$. Patients with higher NAPSI had a higher frequency of TS changes $\left(r_{s}=0.459\right.$, $p<0.001$ ). Trilaminar structure changes were also correlated with presence of clinical nail psoriasis $\left(r_{s}=0.328\right.$ $p<0.001)$ and with MASES $\left(\mathrm{r}_{\mathrm{s}}=0.249 p=0.006\right)$.

Independent variables explaining the main ultrasonographic nail changes according to the linear regression model are shown in Table 3.

\section{Discussion}

Ultrasonography can be employed as a method for early detection and careful characterization of the inflammatory process in different anatomical structures and different stages of the disease in patients with $\mathrm{PsO}$ and PsA [11]. Since the nail apparatus can be considered a part of the musculoskeletal system and a link between joint and tegument [31], US nail evaluation has emerged as a promising tool for early identification of nail psoriasis, as a possible technique for distinguishing $\mathrm{PsO}$ from PsA patients and for differentiating psoriatic patients from control group patients [6].

Our study compared gray scale (NPT, NBT, NMT and TS) and power Doppler (NMRI, NBRI) nail measures among PsA, PsO, and control subjects and found that TS and NPT were different in psoriatic patients.

In previous studies, NMRI was higher in PsO patients compared to controls. The authors explained their results by the endothelial disfunction in patients with psoriasis and by capillaroscopic findings in nail folds showing greater tortuosity and decreased capillary density in psoriatic patients $[18,32,33]$. Another study found lower NMRI in PsA patients compared to control subjects, probably due to the close relationship between distal interphalangeal (DIP) enthesis and the nail matrix. 
Table 2 Prevalences and means of outcomes among groups

\begin{tabular}{|c|c|c|c|c|}
\hline & $\begin{array}{l}\text { PsA } \\
(n=123)\end{array}$ & $\begin{array}{l}\text { PsO } \\
(n=139)\end{array}$ & $\begin{array}{l}\text { Controls } \\
(n=138)\end{array}$ & $p *$ value \\
\hline \multicolumn{5}{|c|}{${\text { Trilaminar Structure (Wortsman's Classification) }-\mathrm{n}(\%)^{\dagger}}^{\dagger}$} \\
\hline 0 & $91(74.0)$ & $107(77.0)$ & $137(99.3)^{* *}$ & $<0.001$ \\
\hline 1 & $4(3.3)$ & $9(6.5)^{* *}$ & $1(0.7)$ & \\
\hline$\|$ & $15(12.2)^{* *}$ & $5(3.6)$ & $0(0.0)$ & \\
\hline III & $9(7.3)^{* *}$ & $7(5.0)$ & $0(0.0)$ & \\
\hline IV & $4(3.3)$ & $11(7.9)^{* *}$ & $0(0.0)$ & \\
\hline
\end{tabular}

Degree of PD Nail Matrix and Bed Together- $n(\%)^{\dagger}$

\begin{tabular}{|c|c|c|c|c|}
\hline 0 & $19(17.8)$ & $7(6.5)$ & $10(9.4)$ & $p=0.133$ \\
\hline 1 & $77(72.0)$ & $91(85.0)$ & $84(79.2)$ & \\
\hline 2 & $7(6.5)$ & $8(7.5)$ & $8(7.5)$ & \\
\hline 3 & $4(3.7)$ & $1(0.9)$ & $4(3.8)$ & \\
\hline $\mathrm{NPT}-$ mean $\pm \mathrm{SD}^{\ddagger}$ & $0.73 \pm 0.14^{a}$ & $0.72 \pm 0.15^{a}$ & $0.67 \pm 0.10^{b}$ & $=0.001$ \\
\hline $\mathrm{NBT}-$ mean $\pm \mathrm{SD}^{\ddagger}$ & $1.88 \pm 0.34$ & $1.97 \pm 0.38$ & $1.90 \pm 0.31$ & $=0.085$ \\
\hline $\mathrm{NMT}-$ mean $\pm \mathrm{SD}^{\ddagger}$ & $2.00 \pm 0.32$ & $2.07 \pm 0.37$ & $1.97 \pm 0.36$ & $=0.068$ \\
\hline $\mathrm{NMRI}-$ mean $\pm \mathrm{SD}^{\ddagger}$ & $\begin{array}{l}(n=84) \\
0.49 \pm 0.06\end{array}$ & $\begin{array}{l}(n=95) \\
0.50 \pm 0.07\end{array}$ & $\begin{array}{l}(n=91) \\
0.49 \pm 0.06\end{array}$ & $=0.415$ \\
\hline $\mathrm{NBRI}-$ mean $\pm \mathrm{SD}^{\ddagger}$ & $\begin{array}{l}(n=46) \\
0.51 \pm 0.07\end{array}$ & $\begin{array}{l}(n=83) \\
0.53 \pm 0.07\end{array}$ & $\begin{array}{l}(n=79) \\
0.52 \pm 0.06\end{array}$ & $=0.115$ \\
\hline
\end{tabular}

Legend: $n$ absolute frequency of patients, $S D$ standard deviation, $P_{s} O$ psoriasis, PSA psoriatic arthritis, NPT nail plate thickness, NBT nail bed thickness, NMT nail matrix thickness, NMRI resistance index in nail matrix, NBRI resistance index in nail bed. ${ }^{\dagger}$ Chi-Square Analysis of qualitative variables. ${ }^{\ddagger}$ One-Way ANOVA $p<$ 0.001 ,post hoc Turkey. ${ }^{a}, b_{\text {: }}$ equal letters means there is no difference between means with $p>0.05$; different letters means there is a difference between means with $p<0.05$. * significance fixed on $p<0,05$, ** with statistically significant difference

According to those authors, the DIP enthesis inflammation extends into the nail matrix, resulting in vasodilatation and decreased RI $[19,20]$.

Our results did not confirm previous studies' findings of differences in mean NMRI between PsA, PsO, and control groups. The linear regression analysis did not show any associations between RI measures and $\mathrm{PsO}$ or PsA diagnoses, despite the $>80 \%$ power to detect an effect size of 0.05. This confirms the conclusion that, in our sample, there is no difference in NMRI among groups.

Analyzing mean NMRI data available in the literature, there is a considerable variation in nail RI reported by different authors, particularly for control groups $[18,20$, 32, 33]. Measurement of RI is operator dependent and difficult to standardize, which makes it difficult to compare the results. More studies, with larger samples, that clarify the behavior of NMRI measurement and identify factors that can influence NMRI measures in healthy patients are important to enable study of this parameter in disease.

In larger vessels such as the renal and umbilical arteries, RI has exhibited influence from gender, age, DM, and smoking [21]. However, it still remains to be
Table 3 Linear regression analysis of quantitative outcomes

\section{Nail Matrix RI}

Variable

Multivariate model

Age

Standardized $\beta$

$p$ value*

(Adjusted $R^{2}$ ) $=0,125$

0.002

$<0.001$

Nail Bed RI

Variable

Multivariate model

Age

Gender $^{\text {a }}$

Standardized $\beta$

$p$ value*

(Adjusted $R^{2}$ ) $=0,175$

0.002

$<0.001$

$-0.021$

0.017

Tabagism

0.031

0.015

Nail Matrix Thickness

Variable

Multivariate model

Age

Standardized $\beta$
(Adjusted $R^{2}$ ) =0,332
0.008
0.359
0.148
-0.332

$p$ value*

Gender ${ }^{a}$

$<0.001$

Havy manual labor

Hand Side ${ }^{b}$

$-0.332$

$<0.001$

0.003

$<0.001$

Nail Bed Thickness

Variable

Multivariate model

Standardized $\beta$

$p$ value*

Age

(Adjusted $R^{2}$ ) $=0,270$

0.005

$<0.001$

Havy manual labor

0.167

$<0.001$

Hand Side ${ }^{b}$

$-0.220$

$<0.001$

Fingernail $^{c}$

0.142

$<0.001$

HBP

0.140

$<0.001$

DM

$-0.113$

0.006

Nail Plate Thickness

Variable

Standardized $\beta$

$p$ value*

Multivariate model

(Adjusted $R^{2}$ ) $=0,189$

PsA

0,051

0,001

$\mathrm{PsO}$

0,041

0,006

Age

0.002

$<0.001$

Havy Manual Labor

0.037

0.012

Hand Side ${ }^{b}$

0.035

0.004

smoking

0.099

$<0.001$

DM

$-0.057$

0.001

Legend: $P_{S} O$ psoriasis, $P_{S} A$ psoriatic arthritis, $R I$ resistance index, HBP high blood pressure, $D M$ diabetes mellitus.

${ }^{a} G e n d e r$ positive $\beta$ : variable higher in male gender, negative $\beta$ :variable higher in female gender.

${ }^{\mathrm{b}} \mathrm{Hand}$ Side: positive $\beta$ : variable higher in left side, negative $\beta$ : variable higher in right side.

'Fingernail: positive $\beta$ : variable higher in 2nd fingernal, negative $\beta$ : variable higher in 3rd fingernail.

* significance fixed on $p<0,05$

determined which factors can influence this measure in microcirculation. In the linear regression analysis, NMRI $\left(R^{2}=0.125\right)$ was related to age and NBRI $\left(R^{2}=0.175\right)$, 
increasing with age, and was higher in females and smokers.

Several authors have shown that NPT, NMT, and NBT were greater in psoriatic patients than controls [9, $11,13,14,32,34-38]$. The present study only detected this increase in NPT. However, the mean NPT in each group was higher than those found by previous studies and it is possible that the great variation in measurements in the literature is partly related to ethnic differences [35, 36]. Larger samples could possibly reveal increases in NMT and NBT in psoriatic patients. There was no difference in NPT, NMT, or NBT between PsO and PsA patients. Our results reproduce the higher NPT measures on patients with clinical signs of nail psoriasis found in previous studies. However, our analyses did not result in higher NBT and NMT measures on these patients, as demonstrated in previous studies [32, 36, 37]..

Linear regression analysis demonstrated that NPT values were directly related $\left(R^{2} 0.189\right)$ to age, presence of PsA, having $\mathrm{PsO}$, right hand, heavy manual labor, and smoking habit, and inversely related to DM. A relationship between heavy manual labor and increased NPT and NBT is expected as a result of triggering of the cycle of local microdamage and repair that results in a deep Koebner phenomenon, as occurs in skin [31]. The analysis also revealed a direct relationship between NBT (adjusted for age, HBP, DM, hand side, and fingernail) and heavy manual labor $\left(R^{2}=0.189\right)$.

The TS changes in the NP of psoriatic patients described by Wortsman et al. [8] were evident in the results and although the frequencies of each grade of change in each group of patients were different to those reported in previous studies $[11,36]$, this study was able to differentiate psoriatic patients from control patients on the basis of the presence of these changes. Presence of TS changes had direct correlations with clinical nail involvement, NAPSI, MASES, and NPT. Other authors have shown relationships between TS changes and clinical nail involvement previously [32, 38, 39].

Even though the majority of studies have reported increased PD signal in the NB and NM of psoriatic patients $[11,13,14,32,36,40]$, capillaroscopic evaluation of the proximal nailfold of these patients has shown decreased number and diameter of capillaries and increased vessel tortuosity [41, 42]. In our study, the grade of NMPD signal and PD assessed in the NB and NM together failed to reveal differences between groups and the NBPD signal was more frequently absent in the PsA group. Recently, Naredo et al. [34] demonstrated that neither NBPD or NMPD classified as per Gutierrez et al. [15], nor PD evaluated in the NB and NM together, could discriminate between control and psoriatic groups, or between clinically involved and clinically noninvolved nails. These authors, in common with Aydin et al. [43], demonstrated that the amount of blood flow detected in control subjects is highly variable.

The discrepancies found between our results and those of previous studies may be related to the diversity in ultrasound equipment employed during the data collection phase, especially concerning frequency range, which may have affected the precision of the measurements. Some cited studies $[8,36,33]$ also only focused on $\mathrm{PsO}$ and PsA patients with current clinical psoriatic nails, another possible cause for measurement variations.

Our study has some limitations, such as the equipment used, that had lower frequency, both for GS and PD, when compared with more recent studies, although it is high frequency. The fact that we analyzed only 4 fingernails of which patients also can be considered a limitation. Our study is the first to that compare NMRI and NBRI among these three groups (PsO, PsA, and controls).

\section{Conclusions}

In conclusion, echographic TS characteristics and NPT seem capable of distinguishing between psoriatic nails and controls nails, but not between PsO and PsA patients. Neither NMRI nor the other measures and parameters evaluated in the study could distinguish between psoriatic nails and control nails. Although US nail microcirculation parameters did not demonstrate utility for diagnostic of psoriatic nail, nail GS US is helpful and allows nails from psoriatic patients to be distinguished from those of control patients, even in the absence of clinical signs of nail psoriasis. Future studies are needed to clarify the characteristics and variations of the parameters of nail US in PsO and PsA patients, since there is no consensus to date.

\section{Abbreviations}

BSA: Body surface area; Cl: Confidence interval; CRP: C reactive protein; DAPSA: Disease activity in psoriatic arthritis; DIP: Distal interphalangeal; DM: Diabetes Mellitus; ESR: Erythrocyte sedimentation rate; GS: Gray scale; HBP: High blood pressure; Hz: Hertz; MASES: Maastricht ankylosing spondylitis enthesis score; MDA: Minimal disease activity; MHz: Megahertz; NAPSI: Nail psoriasis severity index; NB: Nail bed; NBRI: Nail bed resistance index; NBT: Nail bed thickness; NM: Nail matrix; NMRI: Nail matrix resistance index; NMT: Nail matrix thickness; NP: Nail plate; NPT: Nail plate thickness; PASI: Psoriasis area and severity index; PD: Power doppler; PsA: Psoriatic Arthritis; PsO: Psoriasis; RI: Resistance Index; SD: Standard Deviation; SDo: Spectral doppler; TS: Trilaminar structure; US: Ultrasonography; VAS: Visual analog scale

\section{Acknowledgements}

Not applicable.

\section{Authors' contributions}

SDDR - Was a contributor in writing the manuscript, in collected the data and in statistical analysis. JAM - Was a contributor in writing the manuscript, in collected the data and in statistical analysis. PEP - Was a contributor in writing the manuscript and in collected the data. CLK - Was a contributor in writing the manuscript and in collected the data. TFC - Was a contributor in writing the manuscript and in collected the data. RMSC - Was a contributor 
in writing the manuscript, in collected the data and in statistical analysis. All authors read and approved the final manuscript.

\section{Funding}

The study had not funding sources.

\section{Availability of data and materials}

The datasets used and/or analysed during the current study are available from the corresponding author on reasonable request.

\section{Declarations}

\section{Ethics approval and consent to participate}

The study was approved by the National Research Ethics Committee of Plataforma Brasil ( $n^{\circ}$ 72762317.4.0000.5327)

All participants consented the participation in the study.

\section{Consent for publication}

All participants consented the publication of the data and collected ultrasonography images.

\section{Competing interests}

The authors declare that they have no competing interests.

\section{Author details}

'Division of Rheumatology, Hospital de Clínicas de Porto Alegre, Universidade Federal do Rio Grande do Sul, Porto Alegre, Brazil. '2Divisiont of Dermatology, Hospital de Clínicas de Porto Alegre, Universidade Federal do Rio Grande do Sul, Porto Alegre, Brazil. ${ }^{3}$ Department of Rheumatology, Celso Pierro Hospital, Pontifícia Universidade Católica de Campinas, São Paulo, Brazil.

Received: 1 March 2021 Accepted: 12 July 2021

Published online: 28 July 2021

\section{References}

1. Tan ES, Chong WS, Tey HL. Nail psoriasis: a review. Am J Clin Dermatol. 2012;13(6):375-88. https://doi.org/10.2165/11597000-000000000-00000.

2. Schons KR, Knob CF, Murussi N, Beber AA, Neumaier W, Monticielo OA. Nail psoriasis: a review of the literature. An Bras Dermatol. 2014;89(2):312-7. https://doi.org/10.1590/abd1806-4841.20142633.

3. Jiaravuthisan MM, Sasseville D, Vender RB, Murphy F, Muhn C. Psoriasis of the nail: anatomy, pathology, clinical presentation, and a review of the literature on therapy. J Am Acad Dermatol. 2007;57(1):1-27. https://doi.org/1 0.1016/j.jaad.2005.07.073

4. Baran R. The burden of nail psoriasis: an introduction. Dermatology. 2010; 221(Suppl 1):1-5. https://doi.org/10.1159/000316169.

5. Raposo I, Torres T. Nail psoriasis as a predictor of the development of psoriatic arthritis. Actas Dermosifiliogr. 2015;106(6):452-7. https://doi.org/1 0.1016/j.ad.2015.02.005

6. Mendonça JA, Aydin SZ, D'Agostino MA. The use of ultrasonography in the diagnosis of nail disease among patients with psoriasis and psoriatic arthritis: a systematic review. Adv Rheumatol. 2019;59(1):41. https://doi.org/1 0.1186/s42358-019-0081-9.

7. Aluja Jaramillo F, Quiasúa Mejía DC, Martínez Ordúz HM, González AC. Nail unit ultrasound: a complete guide of the nail diseases. J Ultrasound. 2017; 20(3):181-92. https://doi.org/10.1007/s40477-017-0253-6.

8. Wortsman CX, Holm EA, Jemec GB, Gniadecka M, Wulf HC. Ultrasonido de Alta Resolucion $(15 \mathrm{MHz})$ em el estudio de la uña psoriatica. Rev Chil Radiol. 2004;10:06-11

9. Gisondi P, Idolazzi L, Girolomoni G. Ultrasonography reveals nail thickening in patients with chronic plaque psoriasis. Arch Dermatol Res. 2012;304(9): 727-32. https://doi.org/10.1007/s00403-012-1274-9.

10. Scarpa R, Manguso F, Oriente A, Peluso R, Atteno M, Oriente P. Is the involvement of the distal interphalangeal joint in psoriatic patients related to nail psoriasis? Clin Rheumatol. 2004;23(1):27-30. https://doi.org/10.1007/ s10067-003-0817-z

11. Sandobal C, Carbó E, Iribas J, Roverano S, Paira S. Ultrasound nail imaging on patients with psoriasis and psoriatic arthritis compared with rheumatoid arthritis and control subjects. J Clin Rheumatol. 2014:20(1):21-4. https://doi. org/10.1097/RHU.0000000000000054.
12. Arbault A, Devilliers $H$, Laroche $D$, Cayot A, Vabres P, Maillefert JF, et al. L'échographie des ongles dans le rhumatisme psoriasique : étude pilote sur la faisabilité, la reproductibilité et la validité de mesure. Rev Rhum. 2016; 83(1):37-43. https://doi.org/10.1016/j.rhum.2015.07.011.

13. Idolazzi L, Gisondi P, Fassio A, Viapiana O, Giollo A, Rossini M, et al. Ultrasonography of the nail unit reveals quantitative and qualitative alterations in patients with psoriasis and psoriatic arthritis. Med Ultrason. 2018;20(2):177-84. https://doi.org/10.11152/mu-1327.

14. Gutierrez M, Filippucci E, De Angelis R, Filosa G, Kane D, Grassi W. A sonographic spectrum of psoriatic arthritis: "the five targets". Clin Rheumatol. 2010;29(2):133-42. https://doi.org/10.1007/s10067-009-1292-y.

15. Gutierrez M, Di Geso L, Salaffi F, et al. Development of a preliminary US power Doppler composite score for monitoring treatment in PsA. Rheumatology (Oxford). 2012;51(7):1261-8. https://doi.org/10.1093/rheuma tology/kes014.

16. Terslev L, Torp-Pedersen S, Qvistgaard E, Von Der Recke P, Bliddal H. Doppler ultrasound findings in healthy wrists and finger joints. Ann Rheum Dis. 2004;63(6):644-8. https://doi.org/10.1136/ard.2003.009548.

17. Terslev L, Torp-Pedersen S, Qvistgaard E, Bliddal H, Terslev L. Spectral Doppler and resistive index a promising tool in ultrasonographic evaluation of inflammation in rheumatoid arthritis. Acta Radiol. 2003:44(6):645-52. https://doi.org/10.1046/j.1600-0455.2003.00136.x.

18. Husein El-Ahmed H, Garrido-Pareja F, Ruiz-Carrascosa JC, Naranjo-Sintes R. Vessel resistance to blood flow in the nailfold in patients with psoriasis: a prospective case-control echo Doppler-based study. Br J Dermatol. 2012; 166(1):54-8. https://doi.org/10.1111/j.1365-2133.2011.10579.x.

19. Mendonça JA. As diferenças do Doppler espectral, na artrite psoriática e onicomicose. Rev Bras Reumatol. 2014;54(6):490-3. https://doi.org/10.1016/j. rbr.2014.03.029.

20. Mendonça JA, Nogueira JC, Laurido IMM, Vierhout C, Peron F, Lyrio AM. SAT0191 Can spectral doppler identify nail enthesitis in psoriatic arthritis?[Abstract]. Ann Rheum Dis. 2014;73:659.

21. Cauwenberghs N, Kuznetsova T. Determinants and prognostic significance of the renal resistive index. Pulse. 2016;3(3-4):172-8. https://doi.org/10.1159/ 000442445.

22. Taylor W, Gladman D, Helliwell P, Marchesoni A, Mease P, Mielants H. Classification criteria for psoriatic arthritis: development of new criteria from a large international study. Arthritis Rheum. 2006;54(8):2665-73. https://doi. org/10.1002/art.21972

23. Frederiksson T, Pettersson U. Severe psoriasis: oral therapy with a new retinoid. Dermatologica. 1978;157(4):238-44. https://doi.org/10.1159/0002 50839.

24. Rich P, Scher RK. Nail psoriasis severity index: a useful tool for evaluation of nail psoriasis. J Am Acad Dermatol. 2003;49(2):206-12. https://doi.org/10.1 067/S0190-9622(03)00910-1.

25. Schoels M, Aletaha D, Funovits J, Kavanaugh A, Baker D, Smolen JS. Application of the DAREA/DAPSA score for assessment of disease activity in psoriatic arthritis. Ann Rheum Dis. 2010;69(8):1441-7. https://doi.org/10.113 6/ard.2009.122259.

26. Heuft-Dorenbosch L, Spoorenberg A, van Tubergen A, Landewé R, van ver Tempel $\mathrm{H}$, Mielants $\mathrm{H}$, et al. Assessment of enthesitis in ankylosing spondylitis. Ann Rheum Dis. 2003;62(2):127-32. https://doi.org/10.1136/ard 62.2.127.

27. Coates LC, Fransen J, Helliwell PS. Defining minimal disease activity in psoriatic arthritis: a proposed objective target for treatment. Ann Rheum Dis. 2010;69(01):48-53. https://doi.org/10.1136/ard.2008.102053.

28. Cauli A, Gladman DD, Mathieu A, et al. Patient global assessment in psoriatic arthritis: a multicenter GRAPPA and OMERACT study. J Rheumatol. 2011;38(5):898-903. https://doi.org/10.3899/jrheum.100857.

29. Cunha JS, Qureshi AA, Reginato AM. Nail Enthesis Ultrasound in Psoriasis and Psoriatic Arthritis: a Report from the 2016 GRAPPA Annual Meeting. J Rheumatol. 2017:44(5):688-90. https://doi.org/10.3899/jrheum.170146.

30. Agresti A. Modelling patterns of agreement and disagreement. Stat Methods Med Res. 1992;1(2):201-18. https://doi.org/10.1177/096228029200100205.

31. McGonagle D, Tan AL, Benjamin M. The nail as a musculoskeletal appendage - implications for an improved understanding of the link between psoriasis and arthritis. Dermatology. 2009;218(2):97-102. https:// doi.org/10.1159/000182250.

32. Marina ME, Botar Jid C, Bolboaca SD, Bocsa C, Mihu CM, Tătaru AD. Highfrequency sonography in the evaluation of nail psoriasis. Med Ultrason. 2016;18(3):312-7. https://doi.org/10.11152/mu.2013.2066.183.hgh. 
33. Bakirci Ureyen S, Kara RO, Erturk Z, Yaldiz M. The microvascular and morphostructural changes of nails in psoriatic patients with nail disease; a link between ultrasound and videocapillaroscopy findings in the nailfold. Med Ultrason. 2018;20(2):185-91. https://doi.org/10.11152/mu-1274.

34. Naredo $\mathrm{E}$, Janta I, Baniandrés-Rodríguez $\mathrm{O}$, et al. To what extend is nail ultrasound discriminative between psoriasis, psoriatic arthritis and healthy subjects? Rheumatol Int. 2019;39:697-705.

35. Ally Essayed SM. al-Shatouri MA, Nasr Allah YS, Atwa MA. Ultrasonographic characterization of the nails in patients with psoriasis and onychomycosis. Egypt J Radiol Nucl Med. 2015;46(3):733-9. https://doi.org/10.1016/j.ejrnm.2 015.04.009.

36. Krajewska-Włodarczyk M, Owczarczyk-Saczonek A, Placek W, Wojtkiewicz M, Wiktorowicz A, Wojtkiewicz J. Ultrasound assessment of changes in nails in psoriasis and psoriatic arthritis. Biomed Res Int. 2018;9:8251097.

37. Aydin SZ, Castillo-Gallego C, Ash ZR, et al. Ultrasonographic assessment of nail in psoriatic disease shows a link between onychopathy and distal interphalangeal joint extensor tendon enthesopathy. Dermatology. 2013; 225:231-5.

38. Acquitter M, Misery L, Saraux A, Bressollette L, Jousse-Joulin S. Detection of subclinical ultrasound enthesopathy and nail disease in patients at risk of psoriatic arthritis. Joint Bone Spine. 2017;84(6):703-7. https://doi.org/10.101 6/j.jbspin.2016.10.005.

39. Mondal S, Dutta S, Lahiri D, Sinha D, Sircar G, Mandal AK, et al. Assessment of nail unit structures by ultrasound in patients with psoriatic arthritis and their correlations with disease activity indices: a case-control study. Rheumatol Int. 2018;38(11):2087-93. https://doi.org/10.1007/s00296-018-41 60-8.

40. Moya Alvarado P, Roé Crespo E, Muñoz-Garza FZ, López-Ferrer A, Laiz Alonso A, Vilarrassa Rull E, et al. Subclinical enthesopathy of extensor digitorum tendon is highly prevalent and associated with clinical and ultrasound alterations of the adjacent fingernails in patients with psoriatic disease. J Eur Acad Dermatol Venereol. 2018;32(10):1728-36. https://doi. org/10.1111/jdv.15035

41. Ferrari Ribeiro C, Beatriz E, Siqueira D, Holler AP, Fabrício L, Skare TL. Periungual capillaroscopy in psoriasis Capilaroscopia periungueal em psoríase. An Bras Dermatol. 2012;87(4):550-3. https://doi.org/10.1590/S036505962012000400005

42. Graceffa D, Amorosi B, Maiani E, et al. Capillaroscopy in psoriatic and rheumatoid arthritis: a useful tool for differential diagnosis. Arthritis. 2013; 2013:957480.

43. Aydin SZ, Gallego CC, Ash Z, Marzo-Ortega H, Wakefield RJ, McGonagle D. Vascularity of Nail Bed by Ultrasound to Discriminate Psoriasis, Psoriatic Arthritis and Healthy Controls.[Letter]. Clin Exp Rheumatol. 2017;35:872.

\section{Publisher's Note}

Springer Nature remains neutral with regard to jurisdictional claims in published maps and institutional affiliations.

\section{Ready to submit your research? Choose BMC and benefit from:}

- fast, convenient online submission

- thorough peer review by experienced researchers in your field

- rapid publication on acceptance

- support for research data, including large and complex data types

- gold Open Access which fosters wider collaboration and increased citations

- maximum visibility for your research: over $100 \mathrm{M}$ website views per year

At $\mathrm{BMC}$, research is always in progress.

Learn more biomedcentral.com/submissions 